\title{
Preventive Effect and Safety of a Follicle Stimulating Hormone Inhibitory Formulation Containing a Mixture of Coicis Semen and Artemisia capillaris for Precocious Puberty: A Preliminary Experimental Study Using Female Rats
}

\author{
Tuy An Trinh, ${ }^{1}$ Seung Chan Park, ${ }^{2}$ Jihong Oh, ${ }^{1}$ Chang-Eop Kim, ${ }^{1}$ Ki Sung Kang, \\ Hwa Seung Yoo, ${ }^{3}$ and Hye Lim Lee ${ }^{1}$ \\ ${ }^{1}$ College of Korean Medicine, Gachon University, Seongnam, Republic of Korea \\ ${ }^{2}$ Highki Korea Medicine Clinic, 6 Dong 5F, 205, Shinbanpo-ro, Seocho-gu, Seoul, Republic of Korea \\ ${ }^{3}$ East West Cancer Center, Dunsan Korean Medicine Hospital of Daejeon University, Daejeon, Republic of Korea \\ Correspondence should be addressed to Hwa Seung Yoo; altyhs@dju.kr and Hye Lim Lee; hanilim@gachon.ac.kr
}

Received 2 August 2017; Revised 29 September 2017; Accepted 16 October 2017; Published 20 November 2017

Academic Editor: Darren R. Williams

Copyright (C) 2017 Tuy An Trinh et al. This is an open access article distributed under the Creative Commons Attribution License, which permits unrestricted use, distribution, and reproduction in any medium, provided the original work is properly cited.

Background. Precocious puberty is a common endocrine disease in children. Inappropriate activation of hypothalamic-pituitary-gonadal axis leads to the development of secondary sexual characteristics at an earlier age than normal children and causes short stature in adulthood. Objectives. The aim of this study is to evaluate the preventive effects of a herbal formulation containing a mixture of Coicis Semen and Artemisia capillaris (hEIF extract) on precocious puberty. Methods. The preventive effect of hEIF extract on precocious puberty in rats was evaluated by measuring blood component after 3 weeks of treatment via oral administration. Network pharmacological analyses were performed to predict the bioactive components of hEIF extract. Results. In vivo studies showed that hEIF extract significantly reduced follicle stimulating hormone (FSH) levels. After treatment with $200 \mathrm{mg} / \mathrm{kg}$ of hEIF extract, the FSH level was $5.33 \pm 1.10 \mathrm{ng} / \mathrm{mL}$, whereas the FSH level in the vehicle group was $46.73 \pm 0.80 \mathrm{ng} / \mathrm{mL}$. Moreover, the use of hEIF extract did not stimulate body growth and bone accretion in rats. The network pharmacological analysis led to the identification of multiple targets of hEIF extract related to lipolysis and the female sex hormone-related pathways. Conclusion. hEIF extract can be used as an FSH inhibitor for the treatment of precocious puberty.

\section{Introduction}

Precocious puberty is defined as the onset of pubertal changes before age 8 in girls and before age 9 in boys. Signs or symptoms of precocious puberty include early pubertal development, rapid bone maturation, decreased adult height, inappropriate body shape, and mental behavioral abnormalities. As the number of patients with precocious puberty increases year after year, more parents have expressed concerns about the negative effect on their children's growth [1]. The early maturation of the hypothalamus-pituitary-gonad (HPG) axis is associated with gonadotropin-dependent (central/true) precocious puberty, and inactivation of the HPG axis is associated with gonadotropin-independent (peripheral/pseudo) precocious puberty [2].
Precocious puberty is 5-10 times more common in girls than in boys. Among girls, approximately $90 \%$ of cases are idiopathic, whereas up to $75 \%$ of cases among boys are found to involve central nervous system abnormalities. The underlying causes of idiopathic precocious puberty have not been elucidated; the normal puberty mechanism is expressed too early [3]. The majority of precocious puberty cases is idiopathic, but environmental factors that mimic hormones and substrates (endocrine-disrupting chemicals), as well as organic lesions, can exert estrogenic activity or increase endogenous estrogen secretion. Androgen- and estrogencontaining substances, such as estrogen-containing cosmetics and food items, and some pharmacological insecticides can interfere with the HPG axis and result in iatrogenic precocious puberty $[4,5]$. 
Although there is no normal index of puberty in Korea, similar to other countries, the age of menarche and breast development have shown a gradual decrease worldwide. Obesity has been shown to accelerate the age of menarche in girls. The number of high-risk obese children has increased owing to a general reduction in physical activity and an increase in the intake of high-calorie foods, such as fast food [6]. Precocious puberty is usually managed with 4-week treatment with depot formulations that deliver gonadotropin-releasing hormone $(\mathrm{GnRH})$. However, the side effects may include headache, nausea, and facial flushing during treatment [7].

In our ongoing search to find herbal formulations for the treatment of precocious puberty, we identified a possible treatment that comprises a mixture of two herbs, Semen Coicis and Artemisia capillaris Thunberg (A. capillaris). Coicis Semen is a ripe seed of Coix lacryma-jobi L. var. mayuen Stapf. and has been used for the treatment of diuresis, analgesia, gynecological issues, edema, neuralgia, rheumatism, and bladder stones and for its tonic effects $[8,9]$. Coicis Semen is reported to contain stigmasterol, sitosterol, vitamin B1, vitamin E, linoleic acid, and other active ingredients that are effective against obesity [8]. A. capillaris, a perennial mugwort from the Asteraceae family [10], is reported to promote liver function and fat decomposition [11]. Quercetin, eupalitin, sitosterol, vitamin A, and various minerals are found in A. capillaris $[12,13]$. In this study, we demonstrated the ameliorative potential of Coicis Semen and A. capillaris formulation administered to female rats with precocious puberty. Moreover, we investigated the mechanism of action of the formulation at systems level by applying network pharmacological analysis. This novel approach offers an opportunity to understand the complex mechanism of the herbal formulations containing multiple compounds.

\section{Materials and Methods}

2.1. Chemicals and Reagents. ELISA kits to detect alkaline phosphatase (ALP) activity and the concentrations of estradiol, osteocalcin, IGF-1, IGFBP-3, luteinizing hormone (LH), and follicle stimulating hormone (FSH) were purchased from R\&D Systems (Minneapolis, USA).

2.2. Preparation of the Herbal Formulation to Prevent Precocious Puberty. Dried Coicis Semen and A. capillaris were purchased from Kyoungdong Herbal Market, Seoul, in July 2015. The ethanolic extracts of Coicis Semen and A. capillaris mixture in the ratio $1: 1$ were prepared (herbal estrogen inhibition formulae (hEIF) extract) as a dried powder by Hanpoong Pharmaceutical Co., Ltd. (Seoul, Korea) and used.

2.3. Experimental Animal and Experimental Design. In this study, we followed the Guidelines for Animal Experimentation approved by Gachon University. Sprague-Dawley rats with a mean body weight of $110 \mathrm{~g}$ were given hEIF extract for 3 weeks, and the effects on precocious puberty were identified. The rats were divided into four groups on the basis of their body weight, and the groups received either the control treatment or hEIF extract at different concentrations. The prepared hEIF extract was administered orally at 50, 100, and $200 \mathrm{mg} / \mathrm{kg} \mathrm{BW}$ to rats.

Group 1. Normal $(n=5)$, received water only.

Group 2. hEIF $50(n=5)$, orally administered hEIF extract $(50 \mathrm{mg} / \mathrm{kg})$ as an aqueous solution.

Group 3. hEIF $100(n=5)$, orally administered hEIF extract $(100 \mathrm{mg} / \mathrm{kg})$ as an aqueous solution.

Group 4. hEIF $200(n=5)$, orally administered hEIF extract $(200 \mathrm{mg} / \mathrm{kg})$ as an aqueous solution.

2.4. Measurement of Body Weight, Food Intake, and Body Length. During the experimental period, the dietary intake and the body weight gain of the rats were measured twice per week. The rat body length was measured horizontally from the nose tip and excluded part of the tail length; however, the total length measurement included the tail as well. To measure the femur length at the end of the experiment, the muscles were removed and the linear length from the femoral head to the distal tip of the femur was measured using a caliper.

2.5. Measurement Organ Weight. At the end of the experiment, the dissected organs (liver, kidney, spleen, and ovary) were washed with physiological saline. Moisture was removed with a gauze, and the organ weights were measured.

2.6. Blood Component Analysis. Blood samples were collected in test tubes containing 0.18 M EDTA and centrifuged at $5,000 \mathrm{rpm}$ for $5 \mathrm{~min}$ at $4^{\circ} \mathrm{C}$. The serum ALP activity and concentrations of estradiol, osteocalcin, insulin-like growth factor 1 (IGF-1), IGF binding protein 3 (IGFBP-3), luteinizing hormone (LH), and follicle stimulating hormone (FSH) were analyzed by using the appropriate enzymatic colorimetric kits in accordance with the manufacturer's instructions. Bone mineral density was analyzed using a bone mineral density meter from Doo Yeol Biotech (Seoul, Korea).

2.7. Network Pharmacological Analysis. We obtained herbal compound-target gene information from the Traditional Chinese Medicine Systems Pharmacology Database (TCMSP, http://ibts.hkbu.edu.hk/LSP/tcmsp.php) [14] and set oral bioavailability $(\mathrm{OB}) \geq 30[15]$ and the drug-likeness (DL) index $\geq 0.18$ [16] as the minimum thresholds, which were the default values suggested in TCMSP.

We further analyzed pathways of target genes using the Kyoto Encyclopedia of Genes and Genomes database (KEGG, http://www.genome.jp/kegg/) [17]. After collecting information about compounds, targets, and pathways, we integrated the information as a network graph using Cytoscape.

2.8. Statistical Processing. The experimental results were expressed as average \pm standard error. Statistical analyses were performed using Student's $t$-test or one-way ANOVA. $p<0.05$ was considered statistically significant. 
TABLE 1: Results of body index and weight of organs of the control and test groups after 3 weeks of treatment. ${ }^{*} p<0.05$ compared with the control value.

\begin{tabular}{lcccc}
\hline Index & Control & \multicolumn{3}{c}{ hEIF extract } \\
& & $50 \mathrm{mg} / \mathrm{kg}$ & $100 \mathrm{mg} / \mathrm{kg}$ & $200 \mathrm{mg} / \mathrm{kg}$ \\
\hline Body length except tail $(\mathrm{cm})$ & $17.87 \pm 0.13$ & $17.88 \pm 0.29$ & $18.08 \pm 0.24$ & $18.34 \pm 0.14^{*}$ \\
Body length $(\mathrm{cm})$ & $36.53 \pm 0.50$ & $37.02 \pm 0.44$ & $37.02 \pm 0.42$ & $37.08 \pm 0.32$ \\
Body weight $(\mathrm{g})$ & $172.83 \pm 5.98$ & $190.14 \pm 4.23^{*}$ & $189.46 \pm 5.40^{*}$ & $187.94 \pm 4.56^{*}$ \\
Femur length $(\mathrm{cm})$ & $2.90 \pm 0.05$ & $2.91 \pm 0.07$ & $2.88 \pm 0.02$ & $2.92 \pm 0.05$ \\
Femur weight $(\mathrm{mg})$ & $545.70 \pm 23.16$ & $540.80 \pm 25.52$ & $531.70 \pm 29.46$ & $544.80 \pm 28.37$ \\
Kidney weight $(\mathrm{mg})$ & $1406.00 \pm 87.08$ & $1394.80 \pm 57.29$ & $1347.40 \pm 90.85$ & $1320.00 \pm 84.10$ \\
Liver weight $(\mathrm{mg})$ & $7298.40 \pm 828.43$ & $7419.80 \pm 25.52$ & $7374.20 \pm 884.96$ & $6934.00 \pm 306.75$ \\
Spleen weight $(\mathrm{mg})$ & $363.20 \pm 49.11$ & $422.80 \pm 35.00$ & $419.20 \pm 40.07$ & $385.80 \pm 36.16$ \\
\hline
\end{tabular}

\section{Results and Discussion}

Precocious puberty is a common endocrine disorder that results in the development of secondary sexual characteristics at an earlier age than normal, before 8 years of age in girls and 9 years of age in boys. The incidence of precocious puberty is higher in girls than in boys [18]. Precocious puberty is classified into central precocious puberty (gonadotropin-dependent) and peripheral precocious puberty (gonadotropin-independent) [19]. The incidence of central precocious puberty in Korean girls has increased significantly from 3.3 per 100,000 girls in 2004 to 50.4 per 100,000 girls in 2010 [20]. The growth spurt that results from precocious puberty terminates quickly, which leads to short stature in adulthood. The early appearance of thelarche or menarche can cause emotional distress in some children.

In gonadotropin-dependent cases, the onset of precocious puberty is initiated by early GnRH secretion from the hypothalamus, which inappropriately activates the hypothalamic-pituitary-gonadal axis. GnRH is released from the hypothalamus by the stimulation of neurokinin $\mathrm{B}$ and kisspeptin [18]. GnRH activates the pituitary gland to secrete gonadotropic hormones that lead to an increase in LH and FSH levels [21]. LH stimulates the theca cells in the ovaries to produce androstenedione, whereas FSH promotes aromatase-dependent estradiol synthesis in follicular cells [22]. Estradiol plays an important role in the development of secondary sexual characteristics, such as thelarche, pubarche, and menarche in girls. Additionally, estradiol causes the pubertal growth spurt and accelerates bone maturation (Figure 2).

In our study, we evaluated the beneficial effect of hEIF extract against precocious puberty in vivo using SPF SpragueDawley rats. After 3 weeks of treatment, body growth indexes of the rats from all groups were determined. The rats were subsequently anesthetized to obtain blood samples for component analyses. The ameliorative effect of hEIF extract on precocious puberty was examined by comparing body weights, bone mineral densities, and gonadotropic hormone levels between the experimental and control groups, which are reflective of the changes in pubertal growth and endocrine function.
The body indexes and weights of organs measured after the 3-week treatment period in all groups are presented in Table 1. The body weight and body length except tail length increased slightly in the groups treated with hEIF extract, but there were no differences in the femur length between the control group and the test compound groups. The blood component analyses showed that treatment with hEIF extract caused a decrease in IGF-1 and IGFBP-3 levels, which stimulates proliferation and differentiation [23]. The ALP level and bone mineral density were not changed, implying that hEIF extract did not induce bone accretion (Table 2).

Activation of the HPG axis accelerates growth and bone maturation as a result of the increased synthesis and secretion of sex hormones, as well as growth hormones, such as serum IGF-1. As the rate of bone maturation increases, the epiphyses are fused early, and the final adult height is reduced to values lower than the target height. Thus, the goal of the treatment for precocious puberty is to match pubertal development of the patient's peers and to minimize the reduction in final adult height.

Several therapies, such as $\mathrm{GnRH}$ analogs, progesterone prescriptions, and herbal medicines, have been reported as effective treatments for precocious puberty. The standard treatment for precocious puberty is the use of gonadotropinreleasing hormone agonist (GnRHa). Synthesized GnRHa has a titer 20-150 times higher than that of GnRH present in the human body. Its mechanism of action is to suppress gonadotropin secretion through the desensitization of $\mathrm{GnRH}$ receptor expression in the pituitary gland [24]. For supporting treatment of precocious puberty, herbal medicines have been used to delay pubertal development and promote growth in patients with precocious puberty [25].

Treatment with hEIF extract at 100 and $200 \mathrm{mg} / \mathrm{kg}$ decreased the weight of the ovary (Figure 1(a)). As shown in Table 2, the levels of LH and estradiol were not altered in the test groups compared to that in the control group. However, the level of FSH significantly decreased after treatment with hEIF extract (Figure 1(b)). The level of FSH in the blood decreased markedly after treatment with $200 \mathrm{mg} / \mathrm{kg}$ of hEIF extract to $5.33 \pm 1.10 \mathrm{ng} / \mathrm{mL}$ in comparison with the level in the control group of $46.73 \pm 0.80 \mathrm{ng} / \mathrm{mL}$. The decreased FSH level in hEIF extract-treated groups 


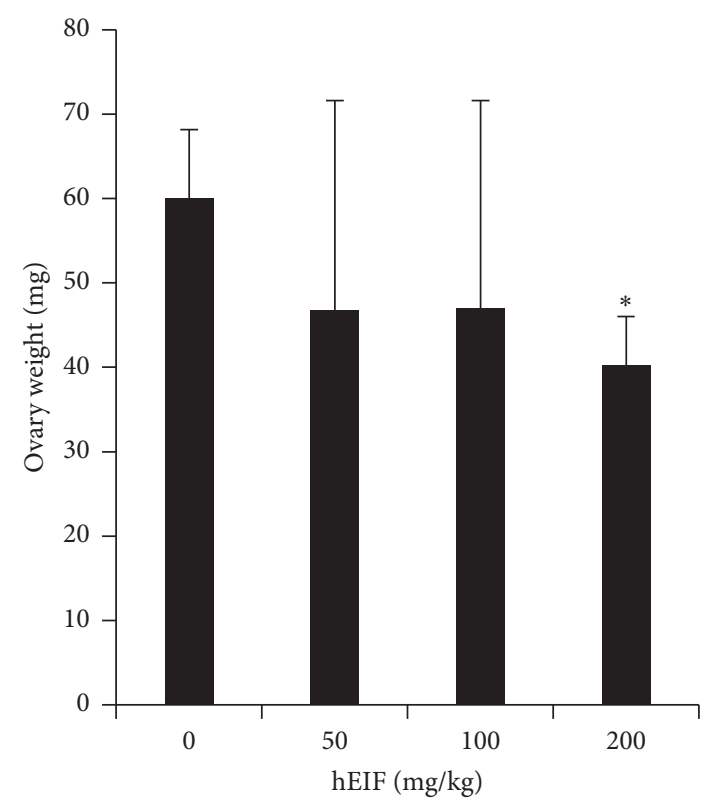

(a)

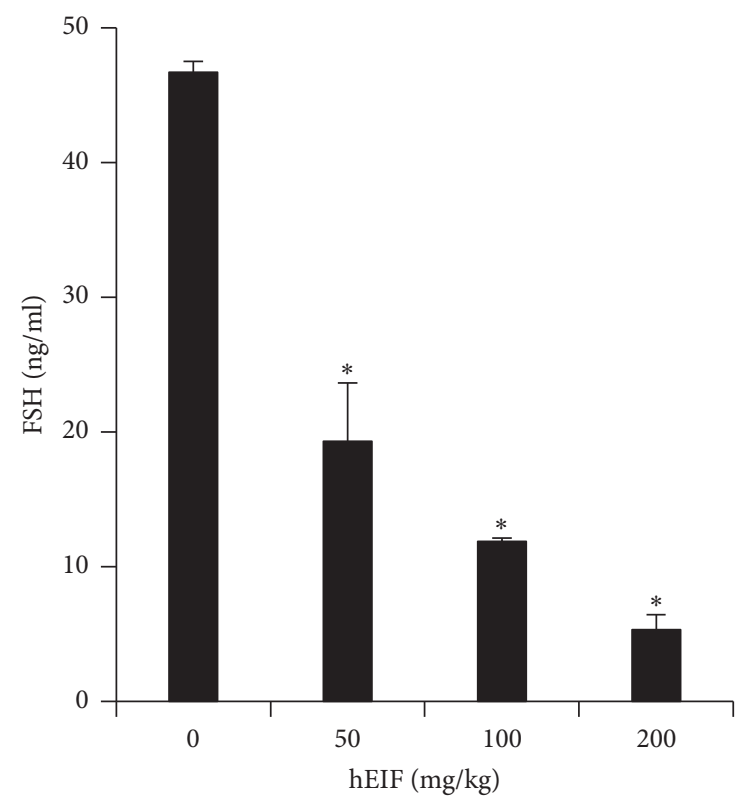

(b)

FIGURE 1: Effects of hEIF formulation on ovary weight and serum FSH concentrations of the control and test groups after 3 weeks of treatment. Sprague-Dawley rats with a mean body weight of $110 \mathrm{~g}$ were given hEIF extract for 3 weeks, and the effects on precocious puberty were identified. The prepared hEIF extract was administered orally at 50,100 , and $200 \mathrm{mg} / \mathrm{kg} \mathrm{BW}$ to rats. ${ }^{*} p<0.05$ compared with the control value. hEIF: herbal estrogen inhibition formulae. FSH: follicle stimulating hormone.

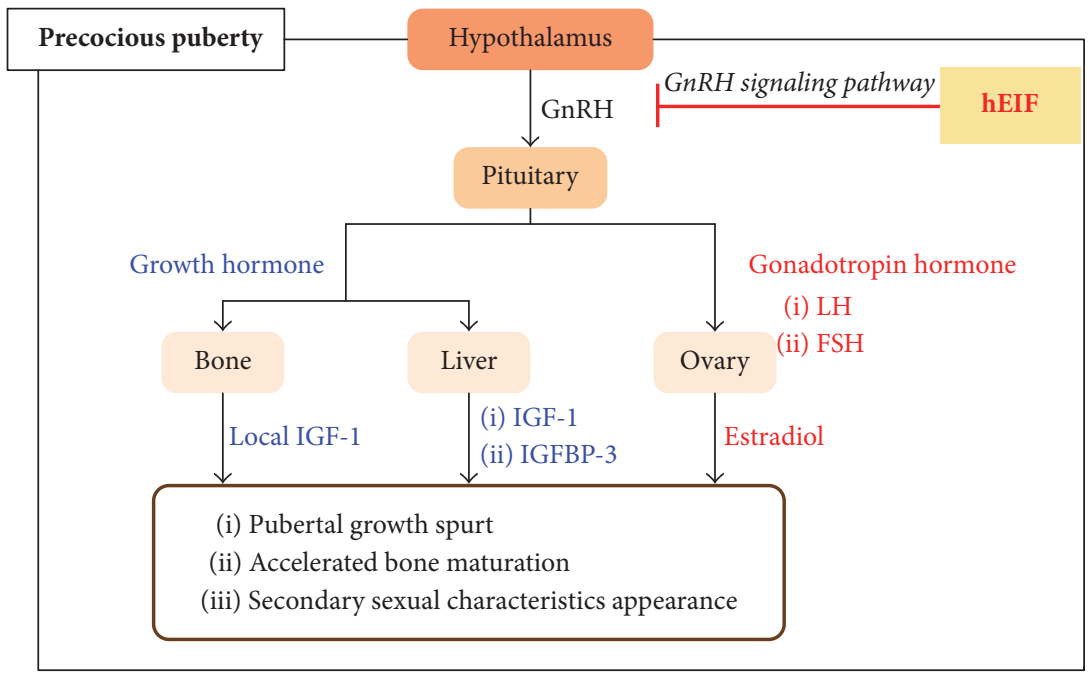

FIGURE 2: Hormonal mechanism scheme of precocious puberty. hEIF: herbal estrogen inhibition formulae.

showed that the oriental herbal formulation functioned as an FSH inhibitor for the prevention of precocious puberty in girls.

Next, network pharmacological analyses were performed to elucidate the complex relationships between the herbal compounds and their targets at the system level. Nine compounds from Coicis Semen and thirteen compounds from A. capillaris with good bioavailability $(\mathrm{OB} \geq 30$ and $\mathrm{DL} \geq$ $0.18)$ were found. Targets of the compounds were predicted by using an in silico model, and the pathways involved were also investigated. On the basis of the KEGG pathway, with an adjusted $p$ value of $\leq 0.05$, identified annotation of the targets was 63 pathways for Coicis Semen and 153 pathways for A. capillaris. Among these pathways, we focused on the regulation of lipolysis and sex hormone-related pathways (estrogen signaling pathway, progesterone-mediated oocyte maturation, oxytocin signaling pathway, and $\mathrm{GnRH}$ signaling pathway). As shown in Tables 3 and 4, 9 and 22 genes were detected, which regulate the pathways of interest associated with Coicis Semen and A. capillaris, respectively. 
TABLE 2: Results of the blood component analysis of the control and test groups after 3 weeks of treatment. ${ }^{*} p<0.05$ compared with the control value.

\begin{tabular}{|c|c|c|c|c|}
\hline \multirow{2}{*}{ Index } & \multirow{2}{*}{ Control } & \multicolumn{3}{|c|}{ hEIF extract } \\
\hline & & $50 \mathrm{mg} / \mathrm{kg}$ & $100 \mathrm{mg} / \mathrm{kg}$ & $200 \mathrm{mg} / \mathrm{kg}$ \\
\hline $\operatorname{ALP}(\mathrm{ng} / \mathrm{mL})$ & $123.54 \pm 4.81$ & $126.19 \pm 3.35$ & $124.79 \pm 4.28$ & $119.89 \pm 2.18$ \\
\hline Bone mineral density $\left(\mathrm{g} / \mathrm{cm}^{2}\right)$ & $0.090 \pm 0.002$ & $0.088 \pm 0.003$ & $0.088 \pm 0.02$ & $0.089 \pm 0.003$ \\
\hline Calcium (mg/dL) & $2.33 \pm 0.64$ & $2.3 \pm 0.59$ & $2.38 \pm 0.65$ & $2.12 \pm 0.50$ \\
\hline Estradiol (pg/mL) & $3.53 \pm 0.21$ & $3.54 \pm 0.19$ & $3.45 \pm 0.35$ & $3.12 \pm 0.39$ \\
\hline Glucose (mg/dL) & $147.00 \pm 24.24$ & $167.80 \pm 19.69$ & $158.80 \pm 19.40$ & $175.80 \pm 16.74$ \\
\hline IGF-1 (ng/mL) & $230.76 \pm 12.12$ & $197.91 \pm 25.69$ & $190.64 \pm 20.17$ & $185.82 \pm 9.57$ \\
\hline IGFBP-3 (ng/mL) & $22.22 \pm 1.05$ & $19.65 \pm 1.49$ & $20.27 \pm 0.45$ & $21.1 \pm 1.05$ \\
\hline $\mathrm{LH}(\mathrm{mIU} / \mathrm{mL})$ & $292.33 \pm 1.23$ & $233.33 \pm 1.63$ & $293.4 \pm 2.26$ & $294.33 \pm 2.13$ \\
\hline Osteocalcin (pg/mL) & $303.30 \pm 4.79$ & $306.90 \pm 18.19$ & $335.91 \pm 14.46$ & $326.83 \pm 12.55$ \\
\hline Total cholesterol (mg/dL) & $62.50 \pm 9.11$ & $60.80 \pm 7.26$ & $56.60 \pm 8.88$ & $67.80 \pm 10.83$ \\
\hline
\end{tabular}

TABLE 3: KEGG pathways related to sex hormones and lipolysis, significantly enriched (adjusted $p$-value of $\leq 0.05$ ) by predicted targets of Coicis Semen.

\begin{tabular}{lccl}
\hline Rank & KEGG pathway & $\begin{array}{c}\text { Adjusted- } \\
p \text { value }\end{array}$ & Genes (targets) \\
\hline $5 / 63$ & $\begin{array}{c}\text { hsa04923: } \\
\text { Regulation of lipolysis } \\
\text { in adipocytes }\end{array}$ & $3.86 E-06$ & $\begin{array}{l}\text { Beta-1 adrenergic receptor; beta-2 adrenergic receptor; } \\
\text { prostaglandin G/H synthase 2; mRNA of PKA catalytic } \\
\text { subunit C-alpha; prostaglandin G/H synthase 1 }\end{array}$ \\
\hline $\begin{array}{c}\text { hsa04914: } \\
\text { Progesterone-mediated } \\
\text { oocyte maturation }\end{array}$ & $4.51 E-03$ & $\begin{array}{l}\text { Cell division protein kinase 2; progesterone receptor; } \\
\text { mRNA of PKA catalytic subunit C-alpha }\end{array}$ \\
\hline $\begin{array}{c}\text { hsa04915: } \\
\text { Estrogen signaling } \\
\text { pathway }\end{array}$ & $\begin{array}{c}\text { hsa04921: } \\
\text { Oxytocin signaling } \\
\text { pathway }\end{array}$ & $\begin{array}{l}\text { Nitric oxide synthase; mRN of PKA catalytic subunit } \\
\text { C-alpha; estrogen receptor }\end{array}$ \\
\hline
\end{tabular}

The compound-target networks were constructed and visualized using Cytoscape [26] to integrate the information about the compound-target interactions and pathways. The compound-target networks consisted of 54 nodes (9 compounds and 45 targets) and 87 edges for Coicis Semen and 126 nodes (13 compounds and 113 targets) and 395 edges for $A$. capillaris. The nodes and edges were colored to indicate the ones associated with the pathways of interest (Figure 3). Multiple targets related to lipolysis and sex hormone-related pathways of hEIF extract were discovered, which indicated the potential effects of Coicis Semen and A. capillaris for the treatment of precocious puberty.

As the results showed, treatment with hEIF extract at dose of $200 \mathrm{mg} / \mathrm{kg}$ significantly reduced the blood level of FSH in SPF Sprague-Dawley rats. More studies will be needed to clarify the role of hEIF extract in the mechanism of FSH release prevention. However, based on the network pharmacological analysis data, hEIF extract is expected to have impact on the GnRH signaling pathway. The binding between $\mathrm{GnRH}$ and its receptor on the cell surface of gonadotrope initiates the signaling cascades that lead to the synthesis of gonadotropins, FSH and LH. The production and secretion of FSH and LH are controlled by the transcription of the distinct $\beta$-subunits $F$ shb and $L h b$, which are stimulated by $\mathrm{GnRH}$ such as mitogen-activated protein kinase cascades, calcium signaling, nuclear factor of activated T-cells transcription factor, and protein kinase A activity [27]. FSH not only promotes the estradiol synthesis in follicular cells, but also stimulates the subsequent growth of prenatal and antral follicles [28]. The decrease in FSH level in the animal group with hEIF extract might cause the difference of ovary weight with the control group through an effect on ovarian follicular development.

In conclusion, we have shown the preventive effects of hEIF extract on precocious puberty by measuring growth indexes and analyzing blood components. We also investigated the systems level mechanism of hEIF extract, which consists of multiple compounds with multiple targets by applying network pharmacological analysis, a novel in silico approach. On the basis of the in vivo experimental results, hEIF extract was identified as an effective therapeutic candidate for precocious puberty inhibitor. Its mechanism of action included reduction in the levels of gonadotropic hormones, such as FSH. Network pharmacological analysis revealed the potential bioactive compounds and their candidate targets, which turned out to be related to lipolysis and sex hormonerelated pathways. Future studies will be conducted to confirm 


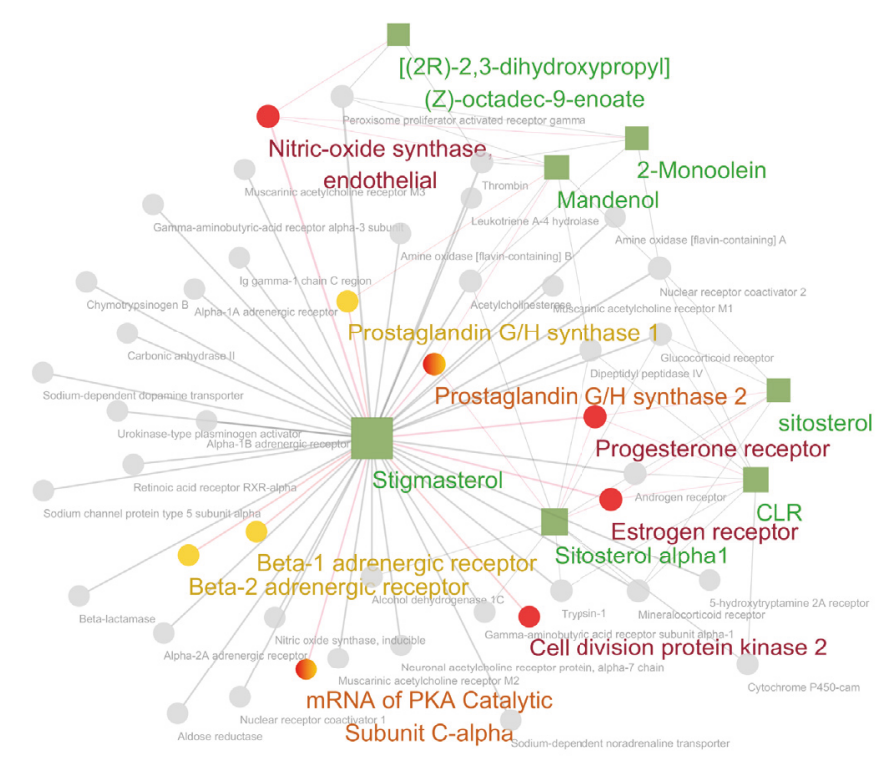

Compound

Target ${ }_{\text {(sex hormone related pathway) }}$

Target (regulation of lipolysis in adipocytes)
Target $_{\text {(intersection targets of sex hormone related pathway }}$ and lipolysis related pathway)

Target ${ }_{(\text {other targets of compounds) }}$

(a)

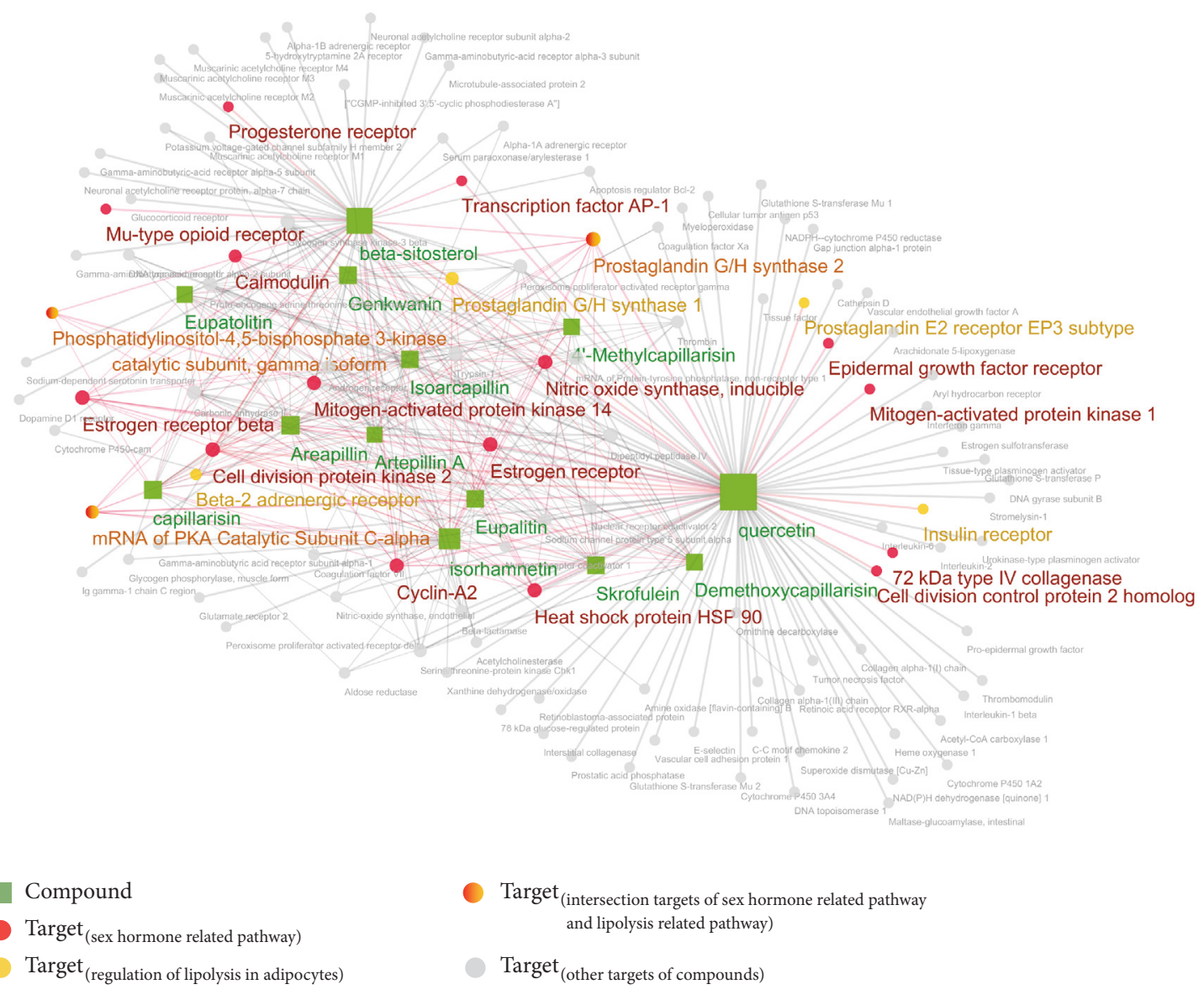

(b)

Figure 3: Compound-target networks of the component herbal formulation for precocious puberty. (a) Coicis Semen. (b) A. capillaris. Rectangles represent compounds $(\mathrm{OB} \geq 30, \mathrm{DL} \geq 0.18)$, and circles represent the target genes. Nodes related to sex hormones or lipolysis regulation in the KEGG pathways are colored. 
TABLE 4: KEGG pathways related to sex hormones and lipolysis, significantly enriched (adjusted $p$-value of $\leq 0.05$ ) by predicted targets of Artemisia capillaris.

\begin{tabular}{|c|c|c|c|}
\hline Rank & KEGG pathway & $\begin{array}{c}\text { Adjusted- } \\
p \text { value }\end{array}$ & Genes (targets) \\
\hline $6 / 153$ & $\begin{array}{l}\text { hsa04915: } \\
\text { Estrogen signaling } \\
\text { pathway }\end{array}$ & $1.25 E-11$ & $\begin{array}{l}\text { Heat shock protein HSP 90; transcription factor AP-1; } \\
\text { nitric oxide synthase; } 72 \mathrm{kDa} \text { type IV collagenase; } \\
\text { mitogen-activated protein kinase 1; Mu-type opioid } \\
\text { receptor; calmodulin; mRNA of PKA catalytic subunit } \\
\text { C-alpha; estrogen receptor; epidermal growth factor } \\
\text { receptor; estrogen receptor beta; } \\
\text { phosphatidylinositol-4,5-bisphosphate 3-kinase } \\
\text { catalytic subunit, gamma isoform }\end{array}$ \\
\hline $17 / 153$ & $\begin{array}{l}\text { hsa04914: } \\
\text { Progesterone-mediated } \\
\text { oocyte maturation }\end{array}$ & $5.57 E-08$ & $\begin{array}{l}\text { Cyclin-A2; cell division control protein } 2 \text { homolog; cell } \\
\text { division protein kinase 2; heat shock protein HSP 90; } \\
\text { mitogen-activated protein kinase 1; mitogen-activated } \\
\text { protein kinase 14; progesterone receptor; } \\
\text { phosphatidylinositol-4,5-bisphosphate } 3 \text {-kinase } \\
\text { catalytic subunit, gamma isoform; mRNA of PKA } \\
\text { catalytic subunit C-alpha }\end{array}$ \\
\hline $28 / 153$ & $\begin{array}{l}\text { hsa04923: } \\
\text { Regulation of lipolysis } \\
\text { in adipocytes }\end{array}$ & $2.11 E-07$ & $\begin{array}{l}\text { Insulin receptor; prostaglandin E2 receptor EP3 } \\
\text { subtype; beta-2 adrenergic receptor; prostaglandin G/H } \\
\text { synthase 2; mRNA of PKA catalytic subunit C-alpha; } \\
\text { phosphatidylinositol-4,5-bisphosphate 3-kinase } \\
\text { catalytic subunit, gamma isoform; prostaglandin G/H } \\
\text { synthase } 1\end{array}$ \\
\hline $57 / 153$ & $\begin{array}{l}\text { hsa04912: } \\
\text { GnRH signaling } \\
\text { pathway }\end{array}$ & $3.07 E-06$ & $\begin{array}{l}\text { transcription factor AP-1; } 72 \mathrm{kDa} \text { type IV collagenase; } \\
\text { mitogen-activated protein kinase 1; mitogen-activated } \\
\text { protein kinase 14; calmodulin mRNA of PKA catalytic } \\
\text { subunit C-alpha; epidermal growth factor receptor }\end{array}$ \\
\hline $70 / 153$ & $\begin{array}{l}\text { hsa04921: } \\
\text { Oxytocin signaling } \\
\text { pathway }\end{array}$ & $9.66 E-06$ & $\begin{array}{l}\text { Transcription factor AP-1; nitric oxide synthase; } \\
\text { mitogen-activated protein kinase 1; calmodulin; mRNA } \\
\text { of PKA catalytic subunit C-alpha; prostaglandin G/H } \\
\text { synthase 2; epidermal growth factor receptor; } \\
\text { phosphatidylinositol-4,5-bisphosphate 3-kinase } \\
\text { catalytic subunit, gamma isoform }\end{array}$ \\
\hline
\end{tabular}

the molecular mechanism and phytochemical composition of hEIF extract that contributes to FSH inhibition.

\section{Conflicts of Interest}

The authors declare that they have no conflicts of interest.

\section{Authors' Contributions}

Tuy An Trinh and Seung Chan Park contributed equally to the work described in this study.

\section{Acknowledgments}

This study was supported by Basic Science Research Program through the National Research Foundation of Korea (NRF), funded by the Ministry of Science, ICT \& Future Planning (NRF-2016R1C1B1012787), and by a 2016 grant from Highki Korea Medicine Clinic through the IndustryAcademic Cooperation Foundation of Daejeon University (201503190001).

\section{References}

[1] M. J. Park, "Recent advance in pathogenesis and treatment of precocious puberty," Journal of Reproduction and Development, vol. 10, no. 4, pp. 215-225, 2006.

[2] M. Berberoğlu, "Precocious puberty and normal variant puberty: Definition, etiology, diagnosis and current management," Journal of Clinical Research in Pediatric Endocrinology, vol. 1, no. 4, pp. 164-174, 2009.

[3] C.-J. Partsch and W. G. Sippell, "Pathogenesis and epidemiology of precocious puberty. Effects of exogenous oestrogens," Human Reproduction Update, vol. 7, no. 3, pp. 292-302, 2001.

[4] A.-S. Parent, G. Rasier, A. Gerard et al., "Early onset of puberty: Tracking genetic and environmental factors," Hormone Research, vol. 64, no. 2, pp. 41-47, 2005.

[5] F. Massart, R. Parrino, P. Seppia, G. Federico, and G. Saggese, "How do environmental estrogen disruptors induce precocious puberty?” Minerva Pediatrica, vol. 58, no. 3, pp. 247-254, 2006.

[6] F. M. Biro, P. Khoury, J. A. Morrison et al., "Influence of obesity on timing of puberty," International Journal of Andrology, vol. 29, no. 1, pp. 272-277, 2006.

[7] Ü. Gül, A. K. Bayram, M. Kendirci et al., "Pseudotumour cerebri presentation in a child under the gonadotropin-releasing 
hormone agonist treatment," Journal of Clinical Research in Pediatric Endocrinology, vol. 8, no. 3, pp. 365-367, 2016.

[8] G. S. Park and S. J. Lee, "Effect of Jobs tears powder and green tea powder on the characteristics of quality of bread," Journal of the Korean Society of Food Science and Nutrition, vol. 28, no. 6, pp. 1244-1250, 1999.

[9] C.-C. Kuo, H.-H. Chen, and W. Chiang, "Adlay (yì yı̆; softshelled job/s tears; The seeds of Coix lachryma-jobi L. var. mayuen Stapf) is a potential cancer chemopreventive agent toward multistage carcinogenesis processes," Journal of Traditional and Complementary Medicine, vol. 2, no. 4, pp. 267-275, 2012.

[10] H. J. Chun, B. Y. Ahn, J. H. Han, and H. W. Woo, "Inhibitory effects of crude polysaccharide of water extract of Artemisia iwayomogi Kitamura on melanin biosynthesis," Yahhak Hoeji, vol. 45, no. 6, pp. 701-707, 2001.

[11] Y. Kiso, S. Ogasawara, and K. Hirota, "Antihepatotoxic principles of Artemisia capillaris buds," Planta Medica, vol. 50, no. 1, pp. 81-85, 1984.

[12] I. J. Seon, Y.-J. Kim, W.-Y. Lee et al., "Scoparone from Artemisia capillaris inhibits the release of inflammatory mediators in RAW 264.7 cells upon stimulation cells by interferon- $\gamma$ plus LPS," Archives of Pharmacal Research, vol. 28, no. 2, pp. 203208, 2005.

[13] S. Seo and K. W. Yun, "Antioxidant Activities of extracts from Artemisia capillaris Thunb. and Artemisia iwayomogi Kitam. used as Injin," Korean Journal of Plant Resources, vol. 21, no. 4, pp. 292-298, 2008.

[14] J. Ru, P. Li, J. Wang et al., "TCMSP: a database of systems pharmacology for drug discovery from herbal medicines," Journal of Cheminformatics, vol. 6, no. 1, article 13, 2014.

[15] X. Xu, W. Zhang, C. Huang et al., "A novel chemometric method for the prediction of human oral bioavailability," International Journal of Molecular Sciences, vol. 13, no. 6, pp. 6964-6982, 2012.

[16] W. Tao, X. Xu, X. Wang et al., "Network pharmacology-based prediction of the active ingredients and potential targets of Chinese herbal Radix Curcumae formula for application to cardiovascular disease," Journal of Ethnopharmacology, vol. 145, no. 1, pp. 1-10, 2013.

[17] M. Kanehisa, S. Goto, Y. Sato, M. Furumichi, and M. Tanabe, "KEGG for integration and interpretation of large-scale molecular data sets," Nucleic Acids Research, vol. 40, no. 1, pp. D109D114, 2012.

[18] E. K. Neely and S. S. Crossen, "Precocious puberty," Current Opinion in Obstetrics and Gynecology, vol. 26, no. 5, pp. 332338, 2014.

[19] D. Long, "Precocious puberty," Pediatrics in Review, vol. 36, no. 7, pp. 319-321, 2015.

[20] S. H. Kim, K. Huh, S. Won, K.-W. Lee, and M.-J. Park, "A significant increase in the incidence of central precocious puberty among Korean girls from 2004 to 2010," PLoS ONE, vol. 10, no. 11, 2015.

[21] J.-C. Carel, N. Lahlou, M. Roger, and J. L. Chaussain, "Precocious puberty and statural growth," Human Reproduction Update, vol. 10, no. 2, pp. 135-147, 2004.

[22] S. A. Divall and S. Radovick, "Endocrinology of female puberty," Current Opinion in Endocrinology, Diabetes and Obesity, vol. 16, no. 1, pp. 1-4, 2009.

[23] D. V. Nguyen, S. Li Calzi, L. C. Shaw, J. L. Kielczewski, H. E. Korah, and M. B. Grant, "An ocular view of the IGF-IGFBP system," Growth Hormone \& IGF Research, vol. 23, no. 3, pp. 45-52, 2013.
[24] J. C. Carel and J. Léger, "Precocious puberty," The New England Journal of Medicine, vol. 358, no. 22, pp. 2366-2377, 2008.

[25] Z. Tian, H. Zhao, Y. Sun, D. Cai, and B. Chen, "Evaluation of the true precocious puberty rats induced by neonatal administration of Danazol: therapeutic effects of nourishing 'Yin'removing 'Fire' Chinese herb mixture," Reproductive Biology and Endocrinology, vol. 3, article 38, 2005.

[26] P. Shannon, A. Markiel, O. Ozier et al., "Cytoscape: a software Environment for integrated models of biomolecular interaction networks," Genome Research, vol. 13, no. 11, pp. 2498-2504, 2003.

[27] I. R. Thompson and U. B. Kaiser, "GnRH pulse frequencydependent differential regulation of $\mathrm{LH}$ and FSH gene expression," Molecular and Cellular Endocrinology, vol. 385, no. 1-2, pp. 28-35, 2014.

[28] C. G. Gervásio, M. P. Bernuci, M. F. Silva-de-Sá, and A. C. J. de Sá Rosa-e-Silva, "The role of androgen hormones in early follicular development," ISRN Obstetrics and Gynecology, vol. 2014, Article ID 818010, 11 pages, 2014. 


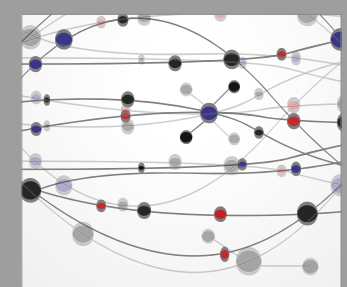

The Scientific World Journal
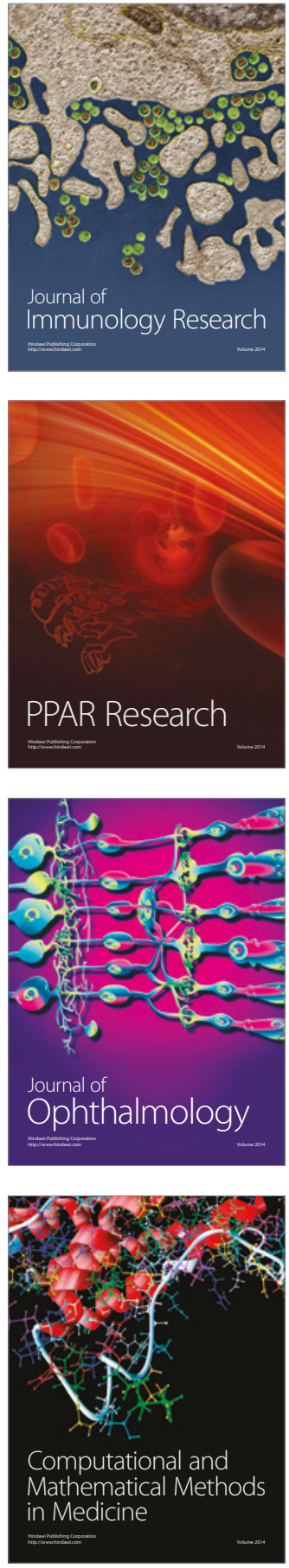

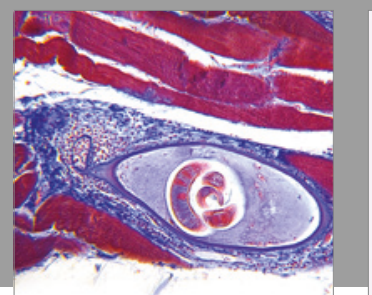

Gastroenterology Research and Practice
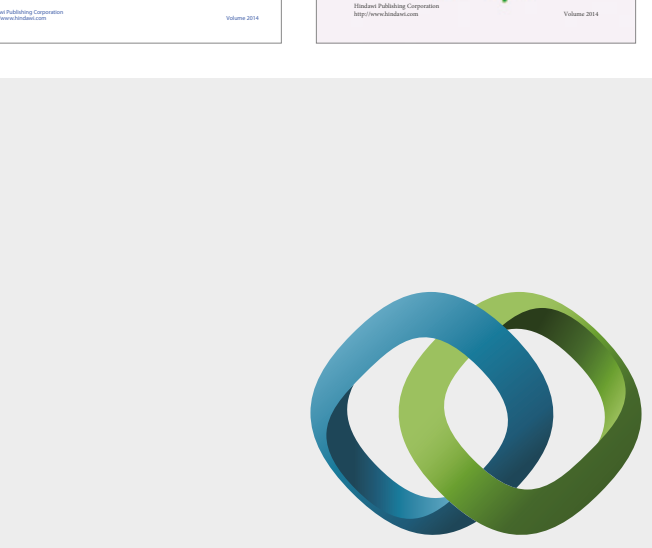

\section{Hindawi}

Submit your manuscripts at

https://www.hindawi.com
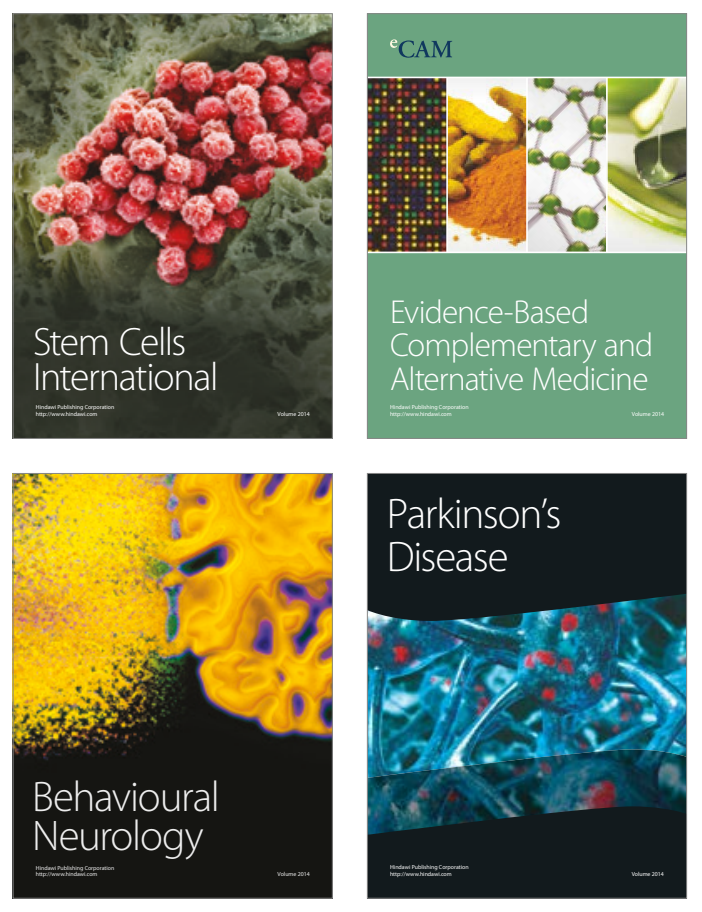
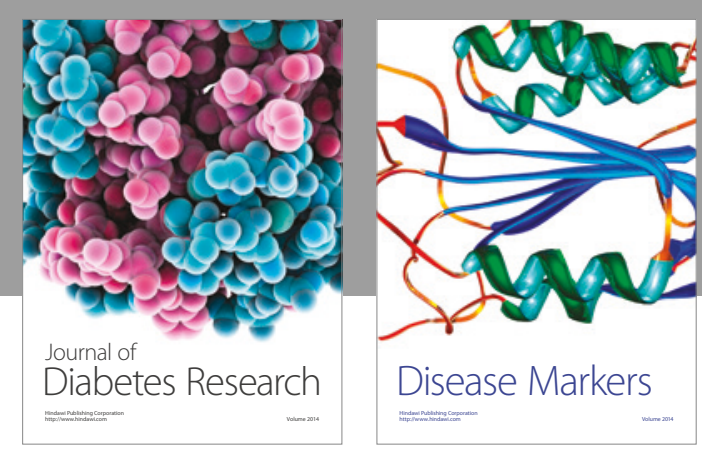

Disease Markers
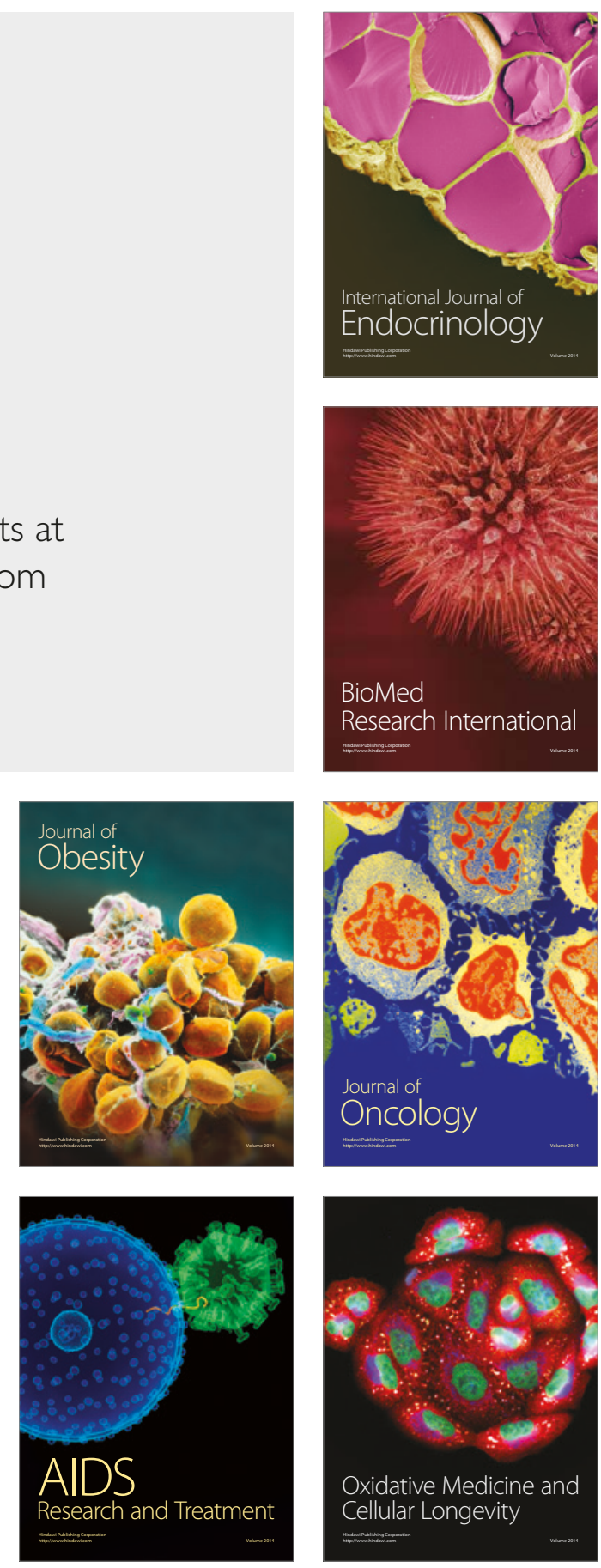